\title{
Combined Vapour Compression Refrigeration System with Ejector usage: A Review
}

\author{
Ganesh Chembedu \\ Dept. of Mechanical Engineering, SJCEM, Palghar, Maharashtra
}

\begin{abstract}
In the present era, common refrigeration system is Vapour Compression Refrigeration System (VCRS) because of its wide applications. Hence, there is a scope of review for the improvement of such application areas. In the present research work, a detailed review of literature has been explored to enhance the performance of simple VCRS. In this paper, a model of combined vapour compression refrigeration system is proposed by adding high EER compressor, diffuser at condenser inlet, passing waste heat from condenser to generator, ejector and fan at evaporator. Based on literature reviewed, suggested modification in VCRS using any one or more of the mentioned components is suggested to give an improved performance over simple VCRS theoretically as well as analytically. Also, combined effect of all the additional components could able to give an appreciable performance in suggested VCRS when relatively compared with Simple VCRS. Present research work will provide a future scope of research in the area of refrigeration and air-conditioning.
\end{abstract}

Keywords: VCRS, modified VCRS, high EER compressor, diffuser, ejector, fan

\section{Introduction}

Refrigeration is a process of reducing and maintaining the temperature below atmospheric temperature. Of the different types of refrigeration systems, Vapour Compression Refrigeration System (VCRS) is most commonly used in domestic applications and Vapour Absorption Refrigeration System (VARS) is used in industrial applications.

The process of Simple VCRS is as follows:

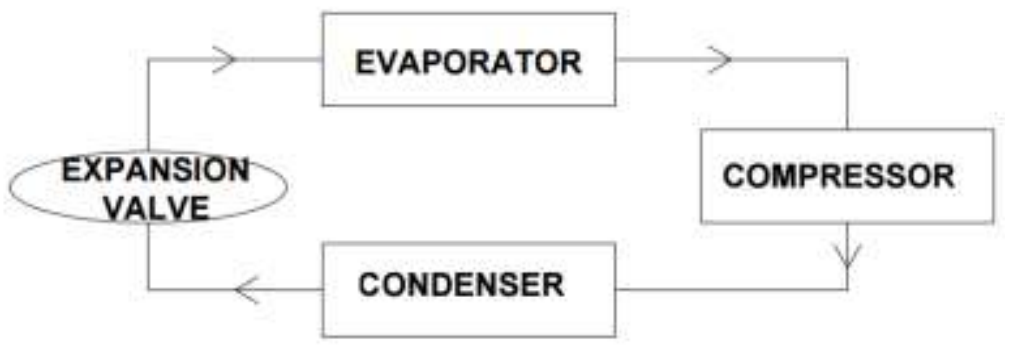

Fig. 1: Simple Vapour Compression Cycle

Compressor: Low pressure and low temperature vapour refrigerant from evaporator gets compressed to high pressure and high temperature vapour refrigerant then passes to condenser. Follows isentropic process

Condenser: Vapour refrigerant gets condensed by rejecting latent heat and changes to liquid state then passes to expansion valve. Follows constant pressure process.

Expansion Valve: Liquid refrigerant pressure, temperature got reduced to low and converts to wet state condition due to throttling then passes to evaporator. Follows isenthalpic process.

Evaporator: Wet refrigerant abstracts latent heat from surroundings/room to be cooled and produces required refrigeration. The refrigerant converts to vapour and passes to compressor to continue the cycle.

The performance of simple VCRS is not appreciable when compared with modified VCRS designed by addition of components to boost its performance. In this paper a new methodology for enhancing the performance of VCRS appreciably is designed and named as Combined Vapour Compression Refrigeration System with Ejector usage.

\section{Literature Review}

Mechanical power distribution losses, Electric motor losses, volumetric efficiency losses and heat losses are the general losses in refrigerant compressor. And for refrigeration, by reducing the power input to the compressor and by minimizing these losses the Energy Efficiency Ratio (EER) is much improved. He proved that when the above modifications were applied to compressor model AWZ5528EXN there was an increase in EER to 3.165 from actual 2.947 which was $6.88 \%$ higher [1]. 
Compressor is to elevate the pressure in vapour compression refrigeration system, but the refrigerant leaving the compressor may cause splashing in the condenser due to high velocity, liquid hump and erode condenser. Hence kinetic energy need to be converted to pressure energy for which diffuser was used. Also used a fan to condenser for sub cooling effect. He concluded that with diffuser and fan, power consumption was less for same refrigerating effect which had resulted in improved performance. He added that the condenser size and cost got reduced due to more heat transfer[2].

By utilizing waste heat from vapour compression cycle condenser to vapour absorption cycle generator, could able to improve the COP by $10.5 \%$. And as load on evaporator section of VCRS increases, more amount of heat can be passed from condenser to generator in the combined VCRS cycle. Thus the performance of combined cycle increases better with increased loads on VCRS [3].

By introducing a fan rotating at higher speed near the evaporator the performance of Vapour compression refrigeration system is improved. Since because of higher fan speed, convection coefficient increased, increasing heat transfer in the evaporator with the surroundings. Thus compressor work is reduced. It increases the efficiency of the normal refrigeration cycle by almost $16 \%$ over the basic cycle by utilizing the energy wasted otherwise [4].

Ejector Expansion Refrigeration Cycle (EERC) increases the efficiency of the modified refrigeration cycle to basic cycle up to $16 \%$. This is due to avoiding of energy wastage in the expansion valve in form of expansion process losses. He added, EERC system has great potential which if used properly could be a very efficient method of refrigeration [5].

\section{Proposed Cycle: Combined Vapour Compression Refrigeration System} With Ejector Usage

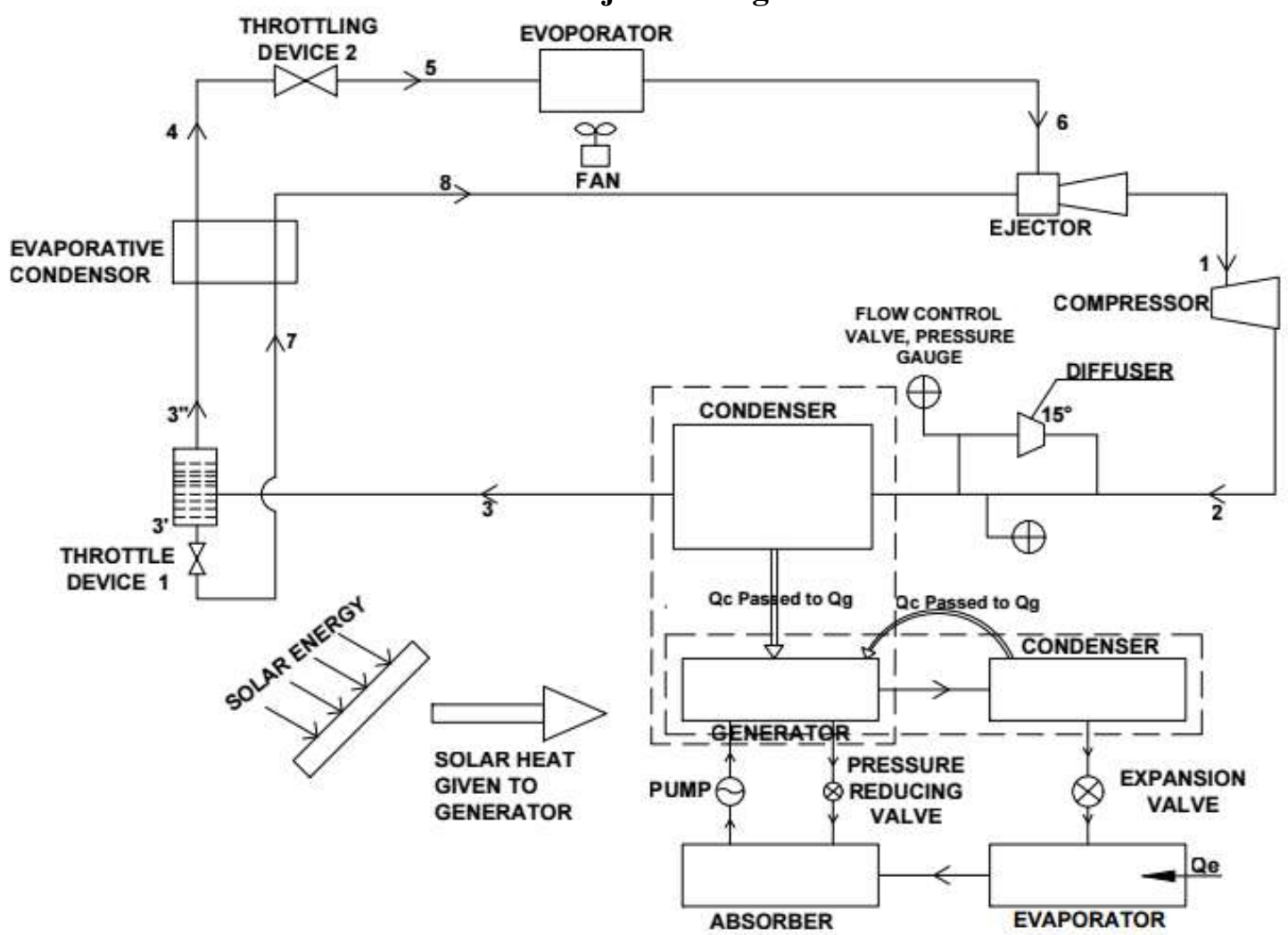

Fig. 2: Combined Vapour Compression Refrigeration System with Ejector Usage Cycle

This new cycle is quite different to simple vapour compression refrigeration system discussed. The difference is due to usage of high energy efficient ratio compressor, diffuser usage before condenser, utilizing waste heat from condenser by giving as an input to generator, usage of ejector and usage of fan at evaporator.

* High Energy Efficient ratio compressor is a compressor with $6.88 \%$ higher performance than an actual compressor [1]. The modifications suggested in the modified compressor were changing the suction path muffler from metal to plastic, super heat temperature is reduced by varying suction head, modifying the suction pressure drops and compressor displacement and and improvements in surface finish 
* Diffuser converts kinetic energy of flowing fluid by raising its pressure. The issue of high velocity refrigerant at condenser inlet is avoided by diffuser. Diffuser minimizes stagnation pressure losses and recovers maximum static pressure which results in less compressor work [6]. Usage of diffuser results in relatively small size condenser and reducing effect of starvation in Vapour compression refrigeration system [7].

- Utilizing waste heat from condenser by passing to generator: With boosting of COP usually refrigeration effect and heat rejected in condenser also increases. Instead of dissipating such a huge valuable rejected condenser heat to atmosphere if supplied to any component which will use it will be more advantageous. Hence waste condenser rejected heat is mapped to Vapour absorption system generator. The combined cycle refrigeration system COP is significantly higher than a single-stage refrigeration system [3].

* Ejector used to reduce throttling losses by replacing the throttling valve in the vapour compression refrigeration system. In addition ejector reduces compressor work by raising suction pressure to much higher than evaporator pressure. Hence COP increased $\quad[9,10$ and 11]. Work recovery (COP improvement) and flash gas bypass (reduction of evaporator size) are the two benefits of ejector usage.

- A high speed Fan at Evaporator circulates warm air across the tubes carrying the cold refrigerant liquid and vapour mixture. The warm air increases the rate of evaporation of liquid in the evaporator and the circulated cold air lowers the enclosed space temperature to the desired value. Hence COP increased [4].

The combined effect of all the components will be more effective in Combined Vapour Compression

Refrigeration System with Ejector Usage Cycle, resulting in an increased COP.

\section{Conclusion}

From the literature reviewed, it's very clear that the performance of simple vapour compression refrigeration system (VCRS) is less and it can be improved. Also, it was proved that addition of any one component like high EER compressor, diffuser at condenser inlet, passing waste heat from condenser to generator, ejector and fan at evaporator in simple VCRS results an improved performance. Hence, the combined effect of all these components together in a single cycle would definitely give an appreciable performance when relatively compared with simple VCRS. Present research work proposes a "Combined Vapour Compression Refrigeration System with Ejector Usage Cycle" as shown in fig. 2. The proposed cycle is self explanatory to give a significantly improved performance. This research work has limitation of experimental analysis to quantify the improved performance. Therefore, future scope of the research in this area is suggested to prove the proposed cycle using experimental analysis as well as system modeling.

\section{References}

[1]. K.Harshavardhan Reddy et al..’'Improvement Of Energy Efficiency Ratio Of Refrigerant Compressor", International Journal of Scientific \& Technology Research ,Volume 2,Issue 5, May 2013

[2]. Neeraj Upadhyay, "To study the effect of Sub-cooling and Diffuser on the Coefficient of Performance of Vapour Compression Refrigeration System",International Journal of Research in Aeronautical and Mechanical Engineering ,Volume 2,Issue 6, June 2014.

[3]. S. N. Vedil et al.,"Waste heat Utilization of vapour compression cycle", International Journal of Scientific and Research Publications, Volume 4, Issue 11, November 2014

[4]. Shireesha Mary $\mathrm{Ch}$ et al., "A Review: Increase in Performance of Vapour Compression Refrigeration SystemUsing Fan",International Journal of Engineering and Applied Sciences, Volume 2, Issue 4, April 2015

[5]. Rounak Sahni, “Ejector Expansion Refrigeration Systems”, International Journal Of Engineering And Science, Voume 5, Issue 2,February 2015.

[6]. Yunus A. Cengel and Michael A. Boles. “Thermodynamics An Engineering Approach”. Tata McGraw-Hill, 2003.

[7]. C. O. Adegoke and M. A. Akintunde, "An Experimental Study of Hunting in Evapourators", A.U. J.T., Vol. 10, No. 1, Jul.-2006, pp. 45-51.

[8]. Satish. K. Maurya, Saurav Avasthi, “Waste Heat Recovery : An Analytical Study of Combined Ejector and Vapour Compression Refrigeration System", International Journal of Engineering Sciences and Research Technology , March 2014

[9]. Yu J, Zhao H, Li Y., "Application of an ejector in autocascade refrigeration cycle for the performance improvement". International Journal Refrigeration 2008;31:279-86.

[10]. Yinhai Zhu et al., "Hybrid vapor compression refrigeration system with an integrated ejector cooling cycle", International Journal of Refrigeration 35 (2012) 68-78

[11]. Jahar Sarkar, "Ejector enhanced vapor compression refrigeration and heat pump systems-A review",Renewable and Sustainable Energy Reviews 16 (2012) 6647-6659 